\title{
The 'upside' of travelers' diarrhea: a personal case report
}

\author{
Stephen B Hanauer
}

The Hanauer family enjoys traveling together during the winter holidays, with recent biking excursions to northern Thailand, the Atacama desert in Chile, and North and South Vietnam, as well as white-water rafting in Costa Rica. While traveling we all enjoy local cuisine, and although we practice appropriate malaria prophylaxis and drink bottled water, have not been overly concerned about gastroenteritis. We consider ourselves as having 'strong stomachs'.

This winter we went on an adventuresome biking trip to Laos. Upon arriving at the World Heritage site of Luang Prabang, our first day was spent accommodating jet lag, discovering the local environs of the town, and enjoying a Laotian feast. The second day entailed a rigorous, 50-mile bike ride through the countryside, followed by massages and, afterwards, dinner with two other families at one of the 'nicer' hotel restaurants. Our group included parents and young adults; some of our party indulged in the local cuisine while the rest craved more 'Western' dishes, including fresh salads.

The next morning I was notified that we had two Hanauers 'down' with urgent diarrhea and that several members of the other families were also affected. In total, 8 of the 13 diners developed profound, nonfebrile, nonbloody diarrhea. A brief epidemiologic survey determined that the 'Western' salads were the culprit, as those of us who ingested only the local cuisine were spared the gastroenteritis. Fortunately, over the next 24 hours most of the victims improved with symptomatic treatment (loperamide or bismuth subsalicylate) and a limited diet, without the need for antibiotics.

Unfortunately, one of my sons had diarrhea and vomiting associated with profound retching that continued over the next day. He was nurtured with tea, rice and blended fruit juices
I now have a

much greater

respect for

the potential

complications

of travelers'

diarrhea

SB Hanauer is Editorin-Chief of Nature

Clinical Practice

Gastroenterology

\& Hepatology.

\section{Competing interests}

The author declared

competing interests; go to

the article online for details.

www.nature.com/clinicalpractice doi:10.1038/ncpgasthep0139 and was able to maintain his hydration. The afternoon of his second day of illness, however, he alerted me to new symptoms: along with a sore throat from retching, he had dysphagia and crepitus (from his jaw to below his clavicles). He had no dyspnea, no tactile fever and his throat was clear aside from some hyperemia. Chest examination was clear to percussion and auscultation (with ears only). Clearly, the retching had caused a potentially fatal perforation of his esophagus-Booerhaave's syndrome-and we were on holiday in a Laotian town with a population of 15,000 and only limited medical care available.

Fortunately, my diagnosis of an upper esophageal tear was incorrect (not being an esophagologist). I was primarily concerned that my son maintained his hydration and avoided an infectious complication. Hospital evaluation, with the potential for nonsterile needles and intravenous fluid administration, was not an option. I gave him ciprofloxacin and continued to nurture him with tea, decarbonated cola from cans, boiled rice, bananas and blended fruit drinks. He could swallow small amounts and maintain his hydration. Over the next five days, he gradually recovered without sequelae.

The esophageal tear wasn't the only 'upside' of this experience-I now have a much greater respect for the potential complications of travelers' diarrhea, although it won't put us off traveling. For our next holiday, we plan to travel to Myanmar (Burma), but we will make sure that our son, in his more vulnerable state, avoids fresh salads.

And for those of you who are interested in finding out more about travelers' diarrhea, a Review by Herbert L DuPont in this issue looks at the current and future antibacterial drugs for its prevention and therapy. 